\title{
The need for supportive care among head and neck cancer patients: psychometric assessment of the Dutch version of the Supportive Care Needs Survey Short-Form (SCNS-SF34) and the newly developed head and neck cancer module (SCNS-HNC)
}

\author{
Femke Jansen $^{1}$ - Birgit I. Witte ${ }^{2}$ C Cornelia F. van Uden-Kraan ${ }^{3}$. \\ Anna M. Braspenning ${ }^{3}$ - C. René Leemans ${ }^{1}$ - Irma M. Verdonck-de Leeuw ${ }^{1,3}$
}

Received: 5 February 2016 / Accepted: 6 June 2016/Published online: 18 June 2016

(C) The Author(s) 2016. This article is published with open access at Springerlink.com

\begin{abstract}
Purpose The purpose of this study is to assess the psychometric properties of the Dutch version of the 34-item Short-Form Supportive Care Needs Survey (SCNS-SF34) and the newly developed module for head and neck cancer (HNC) patients (SCNS-HNC).

Methods HNC patients were included from two cross-sectional studies. Content validity of the SCNS-HNC was analysed by examining redundancy and completeness of items. Factor structure was assessed using confirmatory and exploratory factor analyses. Cronbach's alpha, Spearman's correlation, MannWhitney $U$ test, Kruskall-Wallis and intraclass correlation coefficients (ICC) were used to assess internal consistency, construct validity and test-retest reliability.
\end{abstract}

Electronic supplementary material The online version of this article (doi:10.1007/s00520-016-3307-y) contains supplementary material, which is available to authorized users.

Irma M. Verdonck-de Leeuw

IM.Verdonck@vumc.nl

1 Department of Otolaryngology - Head and Neck Surgery, Cancer Center Amsterdam (CCA), VU University Medical Center, PO Box 7057, 1007 MB Amsterdam, The Netherlands

2 Department of Epidemiology and Biostatistics, VU University Medical Center, PO Box 7057, 1007 MB Amsterdam, The Netherlands

3 Department of Clinical Psychology, EMGO+ Institute for Health and Care Research, Vrije Universiteit Amsterdam, Van der Boechorststraat 1, 1081 BT Amsterdam, The Netherlands
Results Content validity of the SCNS-HNC was good, although some HNC topics were missing. For the SCNS-SF34, a fourfactor structure was found, namely physical and daily living, psychological, sexuality and health system and information and patient support (alpha $=.79$ to .95 ). For the SCNS-HNC, a two-factor structure was found, namely $\mathrm{HNC}$-specific functioning and lifestyle (alpha $=.89$ and .60 ). Respectively, 96 and $89 \%$ of the hypothesised correlations between the SCNS-SF34 or SCNS-HNC and other patient-reported outcome measures were found; 57 and $67 \%$ also showed the hypothesised magnitude of correlation. The SCNS-SF34 domains discriminated between treatment procedure (physical and daily living $p=.02$ and psychological $p=.01$ ) and time since treatment (health system, information and patient support $p=.02$ ). Test-retest reliability of SCNS-SF34 domains and HNC-specific functioning domain was above .70 (ICC $=.74$ to .83 ), and ICC $=.67$ for the lifestyle domain. Floor effects ranged from 21.1 to $70.9 \%$.

Conclusions The SCNS-SF34 and SCNS-HNC are valid and reliable instruments to evaluate the need for supportive care among (Dutch) HNC patients.

Keywords Head and neck cancer - Supportive care needs . Reliability · Validity $\cdot$ Psychometric characteristics $\cdot$ Internal consistency

\section{Introduction}

Head and neck cancer (HNC) patients often experience generic cancer-related problems, such as pain, fatigue [1], anxiety 
[2] and depression [3] as well as HNC-specific problems such as dysphagia [4], or problems with speech [5], nutrition [6] and hearing [7], influencing their quality of life [1, 6]. Supportive care (SC), defined as the prevention and management of adverse effects of cancer and its treatment [8], can help improve these problems.

In order to provide adequate $\mathrm{SC}$ tailored to patients' wishes and needs, insight into their perceived need for $\mathrm{SC}$ is required. A frequently used patient-reported outcome measure (PROM) on generic cancer-related SC needs is the 34-item Short-Form Supportive Care Needs Survey (SCNS-SF34). The SCNSSF34 measures the need and level of need for SC, including physical and daily living, psychological, sexuality, patient care and support and health system and information needs $[9,10]$.

Currently, the SCNS-SF34 has been translated and validated in English [9, 11], French [12], German [13], Italian [14], Mexican [15], Chinese [16, 17] and Japanese [18] populations, including breast [12, 16, 18], colorectal [17], prostate [11] and mixed [9, 13-15] cancer patients. A Dutch translation of the SCNS-SF34 has not been validated so far. In addition, the SCNS-SF34 has not yet been validated among HNC patients. Cross validation of PROMs, when translated into a different language or used in a different cancer population, is of importance, since lingual, cultural and population differences may affect psychometric characteristics.

Supplementary modules for use in conjunction with the SCNS-SF34 have been developed to measure SC needs specific for breast [19, 20], melanoma [21] and prostate [22] cancer patients. Henry et al. [23] added four items (alcohol cessation, smoking cessation, feeling better about my appearance and finding meaning and purpose in life) to the SCNSSF34, which were expected to be relevant to HNC patients; however, these items were not validated. Therefore, we developed an HNC-specific module (SCNS-HNC) by multidisciplinary team discussions consisting of a physician, speech pathologist, linguist, psychologist and health scientist, which we previously used to identify cutoff scores on the European Organisation for Research and Treatment of Cancer (EORTC) head and neck cancer-specific quality of life questionnaire (EORTC QLQ-H\&N35) [24].

The aim of this study was to assess the psychometric properties (i.e. internal consistency, validity and test-retest reliability) of the Dutch version of the SCNS-SF34 and SCNS-HNC in $\mathrm{HNC}$ patients.

\section{Patients and methods}

\section{Design and study participants}

Patients were included from two cross-sectional studies conducted at the Department of Otolaryngology-Head and Neck
Surgery of the VU University Medical Center (VUmc), Amsterdam, The Netherlands. The first study included HNC patients who visited the department from April to September 2013 and who participated in an evaluation study of a touch screen computer-assisted PROM system, which is part of standard clinical practice (called OncoQuest) [25]. After completing OncoQuest, all eligible patients were asked to fill in a questionnaire at home using paper and pencil (including the SCNS-SF34 and SCNS-HNC). In addition, all patients who discussed the results of OncoQuest with an oncology nurse (also part of standard clinical practice) were asked whether they agreed to have a researcher present during this nursing consultation. The researcher completed a study-specific report form regarding this consultation.

The second study included HNC patients who visited the department in February or March 2015. All eligible patients were asked to fill in a questionnaire at home using paper and pencil (including the SCNS-SF34 and SCNS-HNC). In addition, all patients who completed the first questionnaire in this second study were asked to complete the SCNS-SF34 and SCNS-HNC a second time 1-2 weeks later (for test-retest analyses).

Completed questionnaires were sent back to VUmc. In case of missing data, clarifications were sought over the telephone. Patients were included in this particular study when they (1) were treated with curative intent for cancer of the oral cavity, pharynx, larynx, nasal cavity or major salivary glands; (2) were between 3 months and 5 years after last treatment; and (3) were $\geq 18$ years old. Patients were excluded when they had cognitive impairments or did not understand the Dutch language. According to the Dutch Medical Research Involving Human Subjects Act, ethical approval was not necessary, because patients were not subjected to procedures or required to follow rules of behaviour.

\section{Measures}

\section{SCNS-SF34}

The SCNS-SF34 measures the need and level of need for SC in the last month on 34 items on a five-point, two-level response scale $[9,10]$. The first response scale consists of two broad categories of need, i.e. 'no need' and 'need'. The 'no need' scale is further subdivided into 'not applicable' for issues that were no problem to the patient, and 'satisfied' for issues on which a patient needed support but the support was satisfactory. The 'need' category has three subcategories indicating the level of need for additional care, namely 'low need', 'moderate need' and 'high need'. According to the original study of Boyes et al. [9] among mixed cancer patients, SC needs can be subdivided into the following five underlying domains: physical and daily living, psychological, sexuality, 
patient care and support and health system and information. An alternative factor structure was suggested by Au et al. [16] among breast cancer patients, who found four underlying domains using 33 items: physical and daily living, psychological, sexuality and health system, information and patient support. A total score per domain can be calculated and converted to a standardized $0-100$ score, with a higher score indicating a higher level of need [10].

The SCNS-SF34 was translated into Dutch according to the EORTC guideline [26]. A translator and a nurse specialist (both Dutch native speakers) translated the SCNS-SF34 into Dutch. The translations were compared by two of the authors (FJ and IV), and slight discrepancies were solved by discussion in order to provide one Dutch version. By means of back translation, the Dutch version was converted into English by two independently working native English-speaking persons and compared by the two authors to the original English version.

\section{SCNS-HNC}

The SCNS-HNC measures the need for SC concerning 11 HNC-specific issues using the same response scale as the SCNS-SF34. In addition, a single free-text item was added, where patients could report any additional needs, which were not yet taken into account in the SCNS-SF34 or SCNS-HNC. This free-text item was added to analyse whether supportive care needs were missing from the patient perspective. Reading age of the SCNS-HNC calculated using the formula of Douma (formula of Flesch-Kincaid Grade adjusted for Dutch situation) was $13-15$ years [27].

\section{Other PROMs and clinical measures}

All HNC patients also completed the EORTC generic (EORTC QLQ-C30) [28] and HNC-specific (EORTC QLQH\&N35) [29] quality of life measure, the Hospital Anxiety and Depression Scale (HADS) [30], the speech handicap index (SHI) [31] and a PROM evaluating swallowing problems (SWAL-QOL) [32]. In the first study, these PROMs were completed using OncoQuest [25], while in the second, study they were assessed concurrently with the SCNS-SF34 and SCNS-HNC.

Besides, in the first study, a study-specific report form was completed by an observing researcher, who was present during the nursing consultation following OncoQuest. This report form included information on topics, information and SC options discussed during the nursing consultation.

Finally, socio-demographic characteristics were patient-reported, and clinical characteristics were retrieved from patients' medical records.

\section{Data analyses}

Content validity of the SCNS-HNC was analysed by examining redundancy and completeness of items. Items were considered redundant if $<10 \%$ of the patients reported a need (or in case of SCNS-HNC item $6,<10 \%$ of patients were treated with total laryngectomy). Completeness of the SCNS-HNC was examined by analysing SC needs reported on the freetext item of the SCNS-HNC and analysing needs discussed during the nursing consultation as assessed in the studyspecific report form. If $\geq 5 \%$ of patients reported or discussed an additional SC need, adding this specific need to the SCNSHNC should be considered.

Confirmatory factor analysis was used to analyse whether the original five-factor [9] or alternative four-factor structure [16] of the SCNS-SF34 could be replicated, as proposed by Terwee et al. [33]. Criteria for an acceptable fit were root mean square error of approximation (RMSEA) $<.06$, comparative fit index (CFI) and Tucker-Lewis index-non-normed fit index 2.9. Principal component analysis with varimax rotation of factors with eigenvalues $>1.0$ was used to analyse the factor structure of the SCNS-HNC. Appropriateness of principal component analysis was examined using Bartlett's test of sphericity $(p<.05)$ and the Kaiser, Meyer Olkin index of sampling adequacy $(\mathrm{KMO} \geq .60)$. Internal consistency was assessed using Cronbach's alpha coefficient, that is, a value between .70 and .95 is considered good [33].

To analyse construct validity, a priori hypotheses were formulated regarding the correlation between the SCNS-SF34 (31 hypotheses) or SCNS-HNC (9 hypotheses) and other PROMs (EORTC QLQ-C30, EORTC QLQ-H\&N35, HADS, SHI and SWAL-QOL; presented in Table 1) and expected differences between groups of HNC patients (13 hypotheses). Hypotheses were based on previous studies [9, 11-13, 16, 18, 34-36] and researchers' expectations. Regarding expected differences, it was expected that (1) younger patients (18-60 years) reported a higher level of need than older patients ( $>60$ years) on all domains except for physical and daily living [12, 13, 16, 18, 35]; (2) females reported a higher level of need on the physical and daily living and psychological domain [13], while males reported a higher level of need on the sexuality domain [13, 35]; (3) patients with multimodality treatment reported a higher level of need on all domains but sexuality than patients who received single treatment; and (4) patients long after treatment reported a lower need on the patient care and support and health system and information domains [36]. Correlations were analysed using Spearman's correlation coefficient, since needs were nonnormal distributed. Magnitude of the correlations were defined as moderate $(r=0.30$ to 0.50$)$ or strong $(r>0.50)$ [37]. Differences between groups of HNC patients were analysed using Mann-Whitney U test or Kruskall-Wallis. A $p$ value of $<.05$ was considered statistically significant. The 
Table 1 A priori defined hypotheses regarding the (magnitude of the) correlation of domains of the SCNS-SF34 and items of the SCNS-HNC with other patient-reported outcome measures and the found correlation

\begin{tabular}{|c|c|c|c|c|c|c|c|c|c|c|}
\hline & \multicolumn{5}{|c|}{ SCNS-SF34 } & \multicolumn{5}{|l|}{ SCNS-HNC } \\
\hline & P\&DL & PSY & SEX & $\begin{array}{l}\text { PC\&S } \\
\text { HIS\&PS }\end{array}$ & $\mathrm{HS} \& \mathrm{I}^{\mathrm{e}}$ & $\begin{array}{l}\text { Chewing or } \\
\text { swallowing }\end{array}$ & $\begin{array}{l}\text { Dry mouth and/or } \\
\text { sticky mucus }\end{array}$ & $\begin{array}{l}\text { Problems } \\
\text { with weight }\end{array}$ & $\begin{array}{l}\text { To be informed } \\
\text { on nutrition }\end{array}$ & $\begin{array}{l}\text { Difficulty } \\
\text { speaking }\end{array}$ \\
\hline \multicolumn{11}{|l|}{ HADS } \\
\hline Anxiety & $.48^{\mathrm{a}}$ & $.65^{\mathrm{b}}$ & $.34^{\mathrm{a}}$ & $.51^{\mathrm{a}}$ & $\mathrm{a}$ & & & & & \\
\hline Depression & $.61^{\mathrm{a}}$ & $.64^{\mathrm{b}}$ & $.33^{\mathrm{a}}$ & $.57^{\mathrm{a}}$ & a & & & & & \\
\hline \multicolumn{11}{|l|}{ EORTC-QLQ-C30 } \\
\hline Physical functioning & $-.50^{\mathrm{d}}$ & & & & & & & & & \\
\hline Role functioning & $-.63^{\mathrm{c}}$ & & & & & & & & & \\
\hline Emotional functioning & $-.56^{\mathrm{c}}$ & $-.64^{\mathrm{d}}$ & & $-.47^{\mathrm{c}}$ & c & & & & & \\
\hline Cognitive functioning & $-.43^{\mathrm{c}}$ & $-.47^{\mathrm{c}}$ & & & & & & & & \\
\hline Social functioning & $-.54^{\mathrm{c}}$ & & & & & & & & & \\
\hline Global quality of life & $-.55^{\mathrm{d}}$ & $-.51^{\mathrm{c}}$ & & & & & & & & \\
\hline Fatigue & $.64^{\mathrm{b}}$ & $.55^{\mathrm{a}}$ & & $.52^{\mathrm{a}}$ & & & & & & \\
\hline Pain & $.47^{\mathrm{b}}$ & & & $.42^{\mathrm{a}}$ & & & & & & \\
\hline Dyspnoea & & & & $.19^{\mathrm{a}}$ & & & & & & \\
\hline Sleep/insomnia & $.42^{\mathrm{a}}$ & & & & & & & & & \\
\hline Appetite loss & & $.44^{\mathrm{a}}$ & & $.38^{\mathrm{a}}$ & & & & & & \\
\hline \multicolumn{11}{|l|}{ EORTC QLQ-HN35 } \\
\hline Swallowing & & & & & & $.62^{\mathrm{b}}$ & & & & \\
\hline Dry mouth & & & & & & & $.55^{\mathrm{a}}$ & & & \\
\hline Sticky saliva & & & & & & & $.57^{\mathrm{a}}$ & & & \\
\hline Weight loss & & & & & & & & $.40^{\mathrm{a}}$ & & \\
\hline Weight gain & & & & & & & & $.08^{\mathrm{a}}$ & & \\
\hline Speech & & & & & & & & & & $.61^{\mathrm{b}}$ \\
\hline Sexuality & & & $.47^{\mathrm{a}}$ & & & & & & & \\
\hline \multicolumn{11}{|l|}{ SWAL-QOL } \\
\hline Symptom & & & & & & $.62^{\mathrm{b}}$ & & & & \\
\hline Food selection & & & & & & & & & $.48^{\mathrm{a}}$ & \\
\hline SHI total score & & & & & & & & & & $.64^{\mathrm{b}}$ \\
\hline
\end{tabular}

If the a priori defined hypothesis was supported, the coefficient was italicized

$P \& D L$ physical and daily living, $P S Y$ psychological, $S E X$ sexuality, $P C \& S$ patient care and support, $H S \& I$ health system and information

${ }^{a}$ A positive moderate $(r=.30-.50)$ association was expected

${ }^{\mathrm{b}}$ A positive strong $(r>.50)$ association was expected

${ }^{\mathrm{c}}$ A negative moderate $(r=-.30$ to -.50$)$ association was expected

${ }^{\mathrm{d}}$ A negative strong $(r<-.50)$ association was expected

${ }^{\text {e }}$ Since a four-factor structure was found, we only present correlations of the combined HIS\&PS domain

SCNS-SF34 and/or SCNS-HNC were found to be valid if at least $75 \%$ of the hypotheses were in correspondence with the a priori defined hypotheses [33].

Test-retest reliability was analysed using intraclass correlation coefficients (ICC) with absolute agreement in patients who completed the second questionnaire within 1 month after the first. An ICC value $\geq .70$ has been considered good [33]. Finally, floor or ceiling effects $(>15 \%$ of patients with the lowest or highest possible score) were investigated using frequency tables.
All analyses were performed using the IBM Statistical Package for the Social Science (SPSS) version 22 (IBM Corp., Armonk, NY, USA) and Mplus version 6.11 (Muthen \& Muthen, Los Angeles, CA, USA) [38].

\section{Sample size calculation}

For this study, at least 170 patients were needed for factor analyses (five times the number of SCNS-SF34 items), 50 
patients per subgroup for construct validity analyses and 50 patients for test-retest reliability [33].

\section{Results}

\section{Study sample}

In total, 201 patients were included for content analyses, factor analyses and construct validity analyses; 110 patients for testretest analyses; and 69 patients for content analysis using the study-specific report forms. Socio-demographic and clinical characteristics are presented in Table 2.

\section{Content validity of the SCNS-HNC}

On all SCNS-HNC items, $\geq 10 \%$ of the patients reported a need, indicating that there were no redundant items. Regarding completeness, two of the 201 patients who filled in the SCNS-HNC reported on the free-text item that they had an additional need not yet taken into account in the questionnaire, one indicated to have needs regarding pain and one regarding psychological distress. The study-specific report form of the nursing consultation following OncoQuest revealed some frequently discussed HNC-specific issues not yet included in the SCNS-HNC, namely coughing and breathlessness (23\%), difficulty eating or eating in company (19\%), taste and olfaction (16\%), changes in appetite $(9 \%)$ and mobility of the tongue $(6 \%)$.

\section{Factor analysis and internal consistency}

The five-factor structure as well as the four-factor structure of the SCNS-SF34 could not be replicated in our study sample using confirmatory factor analysis (see supplementary materials). Under the assumption either of correlated factors or of uncorrelated factors, both factor structures had a negative residual variance on item 16 'changes in your sexual relationships'. Therefore, we also performed an analysis, in which item 16 was deleted. In that case, both factor models could not be estimated when assuming correlated factors. When assuming correlated factors, both factor models showed inadequate RMSEA scores. Therefore, an exploratory principal component analysis was performed to investigate the factor structure for use in HNC patients. At first, a new five-factor structure was generated (see supplementary materials), replicating the physical and daily living and sexuality domains and almost replicating the psychological needs and health system, information and patient support domain as reported in $\mathrm{Au}$ et al. [16]. However, the fifth factor comprised four items (item 17-19 and 24) without clear cohesion. Since three out of these four items had high cross loadings (cross loadings .34 to .51), a second principal component analysis was performed without item 19 (which did not have any cross loadings) and forced into four factors, resulting in the same factor structure as in $\mathrm{Au}$ et al. [16]. Although this four-factor structure (Bartlett's test of sphericity $(p<.001)$ and KMO $=.93)$ did not have a good fit of the model using confirmatory factor analyses, this model is nevertheless proposed to be the best model for use in HNC patients with good internal consistency (Cronbach's alpha ranging from .79 (sexuality domain) to .95 (psychological)) (Table 3).

Principal component analysis of the SCNS-HNC showed two underlying constructs, namely HNC-specific functioning and lifestyle (Bartlett's test of sphericity $(p<.001)$ and $\mathrm{KMO}=.88)($ Table 4$)$. Item 6 was not included in the principal component analysis, since it was not correlated $(r<.30)$ with the other items. Internal consistency of HNC-specific functioning domain was good (Cronbach's alpha $=.89$ ), while below .70 for the two-item lifestyle domain (Cronbach's alpha $=.60)$.

\section{Construct validity}

In total, 27 of the 28 (96\%) hypothesised correlations (seven hypotheses on health system, information and patient support were investigated instead of 11 hypotheses when the fivefactor structure would have been replicated) between the SCNS-SF34 and other PROMs were found (Table 1). Sixteen correlations $(57 \%)$ also supported the a priori hypothesised magnitude of correlation. Regarding expected differences, three of the ten hypotheses were confirmed (30\%; Table 5). Patients treated with multi-modality treatment reported a higher need on the physical and daily living $(p=.015)$ and psychological domain $(p=.009)$, while no difference was found for health system, information and patient support $(p=.070)$. Patients long after treatment reported less need for health system, information and patient support than patients short after treatment $(p=.015)$. No significant differences were found regarding gender or age.

Of the SCNS-HNC, 8 of the $9(89 \%)$ hypothesised correlations were found (Table 1). Six correlations (67\%) also supported the a priori hypothesised magnitude of correlation.

\section{Test-retest reliability}

Test-retest reliability of the SCNS-SF34 domains was good (ICC ranged from .74 (sexuality) to .83 (physical and daily living)). Test-retest reliability for HNC-specific functioning was also good (ICC $=.83$ ), while it was slightly lower than .70 for the lifestyle domain $(\mathrm{ICC}=.67)$.

\section{Presence of floor and/or ceiling effects}

On all SCNS-SF34 and SCNS-HNC domains, floor effects were present (Tables 3 and 4). Floor effects (no need for care) 
Table 2 Characteristics of the study samples

\begin{tabular}{|c|c|c|c|}
\hline Characteristics & $\begin{array}{l}\text { Factor analyses and } \\
\text { construct validity }(n=201)\end{array}$ & $\begin{array}{l}\text { Test-retest reliability } \\
(n=110)\end{array}$ & $\begin{array}{l}\text { Content validity } \\
\text { (study specific } \\
\text { report form) } \\
(n=69)\end{array}$ \\
\hline & $\%$ & $\%$ & $\%$ \\
\hline \multicolumn{4}{|l|}{ Age } \\
\hline $18-60$ years & 31.3 & 25.5 & 46.4 \\
\hline$>60$ years & 68.7 & 74.5 & 53.6 \\
\hline \multicolumn{4}{|l|}{ Sex } \\
\hline Male & 66.7 & 72.7 & 63.8 \\
\hline Female & 33.3 & 27.3 & 36.2 \\
\hline \multicolumn{4}{|l|}{ Living arrangements } \\
\hline Living alone & 24.4 & 30.0 & $14.3^{\mathrm{a}}$ \\
\hline Living with partner & 58.7 & 59.1 & 59.2 \\
\hline Living with partner and children & 15.4 & 10.0 & 22.4 \\
\hline Other (e.g. with children) & 1.5 & .9 & 4.1 \\
\hline \multicolumn{4}{|l|}{ Education } \\
\hline Elementary education & 6.5 & 3.6 & $5.8^{\mathrm{a}}$ \\
\hline Lower education & 37.8 & 40.0 & 24.6 \\
\hline Secondary education & 26.9 & 25.5 & 23.2 \\
\hline Higher education & 28.9 & 30.9 & 17.4 \\
\hline \multicolumn{4}{|l|}{ Employment status } \\
\hline Employed (paid/unpaid) & 35.8 & 30.9 & $42.9^{\mathrm{a}}$ \\
\hline Unemployed & 12.5 & 11.8 & 16.3 \\
\hline Housewife/houseman & 3.5 & 3.6 & 4.1 \\
\hline Retired & 48.3 & 53.6 & 36.7 \\
\hline \multicolumn{4}{|l|}{ Tumour site } \\
\hline Oral cavity & 31.3 & 33.6 & 30.4 \\
\hline Pharynx & 36.8 & 35.5 & 36.2 \\
\hline Larynx & 19.9 & 20.9 & 17.4 \\
\hline Nasal cavity & 6.0 & 4.5 & 8.7 \\
\hline Major salivary glands & 6.0 & 5.5 & 7.2 \\
\hline \multicolumn{4}{|l|}{ Disease stage (UICC) } \\
\hline Stage I & 27.9 & 30.9 & 23.2 \\
\hline Stage II & 13.4 & 10.0 & 21.7 \\
\hline Stage III & 16.4 & 16.4 & 18.8 \\
\hline Stage IV & 36.8 & 34.5 & 34.8 \\
\hline Unknown & 5.5 & 8.2 & 1.4 \\
\hline \multicolumn{4}{|l|}{ Type of treatment } \\
\hline Surgery & 25.4 & 25.5 & 27.5 \\
\hline Radiotherapy & 20.4 & 21.8 & 23.2 \\
\hline Surgery and chemoradiation & 8.5 & 7.3 & 5.8 \\
\hline Surgery and radiation & 22.4 & 22.7 & 23.2 \\
\hline Chemoradiation & 23.4 & 22.7 & 20.3 \\
\hline \multicolumn{4}{|l|}{ Time since last treatment } \\
\hline$<1$ year & 38.8 & 34.5 & 44.9 \\
\hline $1-2$ year & 29.9 & 31.8 & 26.1 \\
\hline$>2$ year & 31.3 & 33.6 & 29.0 \\
\hline
\end{tabular}

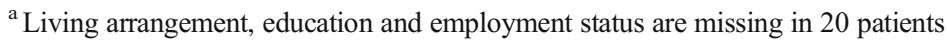


Table 3 Floor and ceiling effects of the SCNS-SF34 and suggested factor structure in head and neck cancer patients $(n=201)$

Item

Physical and daily living

1. Pain

2. Lack of energy/tiredness

3. Feelings unwell a lot of the time

4. Work around the home

5. Not being able to do the things you used to do

Psychological

6. Anxiety

7. Feeling down or depressed

8. Feelings of sadness

9. Fears about the cancer spreading

10. Worry that the results of treatment are beyond your control

11. Uncertainty about the future

12. Learning to feel in control of your situation

13. Keeping a positive look

14. Feelings about death and dying

17. Concerns about the worries of those close to you

Sexuality

15. Changes in sexual feelings

16. Changes in your sexual relationships

31. To be given information about sexual relationships

Health system, information and patient support

18. More choice about which cancer specialists you see

20. Reassurance by medical staff that the way you feel is normal

21. Hospital staff attending promptly to your physical needs

22. Hospital staff acknowledging, and showing sensitivity to your feelings and emotional needs

23. Being given written information about the important aspects of your care

24. Being given information (written, diagrams, drawings) about aspects of managing your illness and side effects at home

25. Being given explanations of those tests for which you would like explanations

26. Being adequately informed about the benefits and side effects of treatments before you choose to have them

27. Being informed about your test results as soon as feasible

28. Being informed about cancer which is under control or diminishing (that is, remission)

29. Being informed about things you can do to help yourself to get well

30. Having access to professional counselling (e.g. psychologist, social worker, counsellor, nurse specialist) if you, your family or friends need it

32. Being treated like a person not just another case

33. Being treated in a hospital or clinic that is as physically pleasant as possible

34. Having one member of hospital staff with whom you can talk to about all aspects of your condition, treatment and follow-up

19. More choice about which hospital you attend

Eigenvalue

Variance

Cronbach's $\alpha$
Factor loadings ${ }^{1}$

\begin{tabular}{llllll}
\hline $\begin{array}{l}\text { Lowest } \\
\text { score }(\%)\end{array}$ & $\begin{array}{l}\text { Highest } \\
\text { score }(\%)\end{array}$ & 1 & 2 & 3 & 4 \\
\end{tabular}

$38.8 \quad 0$

$70.9 \quad 2.5$

$51.0 \quad 4.5$

$74.6 \quad 1.0$

$58.4 \quad 3.0$

$57.7 \quad 7.5$

29.70

$68.0 \quad 2.5$

$67.7 \quad 1.0$

$66.7 \quad 2.0$

$51.5 \quad 8.5$

$59.7 \quad 3.5$

$50.0 \quad 5.5$

$58.0 \quad 1.5$

$54.2 \quad 3.5$

$65.0 \quad 4.5$

$60.5 \quad 2.5$

$69.9 \quad .5$

$75.3 \quad 3.0$

$77.8 \quad 2.5$

$85.4 \quad .5$

21.10

$67.5 \quad 1.5$

$43.5 \quad 2.5$

$57.5 \quad 2.0$

55.0

58.0

61.5

46.2

47.2

43.3

38.3

50.2

66.7

53.2

44.3

44.3

47.3

68.5

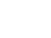

\begin{tabular}{ll}
$.39 \quad .54$ \\
\hline
\end{tabular}

(1)

$$
.33
$$

.54

$.51 \quad .60$
.53

$.53 \quad .67$

.76
-.67

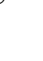

$\begin{array}{lll}.39 & .39 & .69\end{array}$

5

$.78 \quad .31$
.78

$.32 \quad .78$

.81

.85

$.34 \quad .74$

$.33 \quad .82$

$.35 \quad .68$

$.31 \quad .52$

.41

.42

.79

$.38 \quad .42$

.30

.48

$\begin{array}{lll}5 & .47 & .41\end{array}$

$\begin{array}{lll}.5 & .62 \quad .34\end{array}$

.31

.73

.73
.75

$\begin{array}{ll}1.5 & .75\end{array}$

$\begin{array}{ll}2.0 & .75\end{array}$

$4.0 \quad .65$

.30

.72

.31

$\begin{array}{ll}4.5 & .79\end{array}$

$\begin{array}{lll}11.9 & .74 & .31\end{array}$

$\begin{array}{lll}10.4 & .77 \quad .37\end{array}$

$\begin{array}{lll}8.5 & .78 \quad .30\end{array}$

$\begin{array}{lll}4.5 & .67 & .35\end{array}$

$\begin{array}{ll}9.5 & .79\end{array}$

$\begin{array}{ll}6.5 & .72\end{array}$

$6.5 \quad .78$
.74

$.36 \quad .84$

.76

${ }^{\mathrm{a}}$ Loadings $>.3$ are presented, and main (i.e. highest) loading is italicized 
Table 4 Floor and ceiling effects of the SCNS-HNC and suggested factor structure in head and neck cancer patients $(n=201)$

\begin{tabular}{|c|c|c|c|c|}
\hline \multirow[b]{2}{*}{ Item } & \multirow[b]{2}{*}{$\begin{array}{l}\text { Lowest } \\
\text { score }(\%)\end{array}$} & \multirow[b]{2}{*}{$\begin{array}{l}\text { Highest } \\
\text { score }(\%)\end{array}$} & \multicolumn{2}{|c|}{$\begin{array}{l}\text { Factor } \\
\text { loadings }^{\mathrm{a}}\end{array}$} \\
\hline & & & 1 & 2 \\
\hline HNC-specific functioning & 21.3 & 1.0 & & \\
\hline 1. Problems with chewing and or swallowing & 47.0 & 8.0 & .84 & \\
\hline 2. Problems with dry mouth and/or sticky mucus & 36.0 & 10.0 & .85 & \\
\hline 3. Problems with weight (underweight or overweight) & 47.0 & 6.5 & .74 & \\
\hline 4. To be informed on nutrition & 57.5 & 5.0 & .78 & \\
\hline 5. Difficulty speaking & 54.8 & 5.0 & .77 & \\
\hline 7. Problems with hearing & 71.5 & 2.5 & .59 & \\
\hline 8. Oral hygiene & 56.6 & 4.5 & .75 & \\
\hline 9. Problems with mobility of neck or shoulders & 58.8 & 7.0 & .70 & \\
\hline Lifestyle & 70.9 & .5 & & \\
\hline 10. Quit smoking & 81.4 & 5.0 & & .84 \\
\hline 11. Quit drinking & 78.5 & .5 & & .85 \\
\hline 6. Care of your stoma and/or voice prosthesis ${ }^{b}$ & 20.0 & 30.0 & - & - \\
\hline Eigenvalue & & & 4.76 & 1.39 \\
\hline Variance & & & 47.63 & 13.94 \\
\hline Cronbach's $\alpha$ & & & .89 & .60 \\
\hline
\end{tabular}

${ }^{\text {a }}$ Loadings $>.3$ are presented, and main (i.e. highest) loading is italicized

${ }^{\mathrm{b}}$ Percentage of lowest score and percentage of highest score calculated for patients treated with total laryngectomy only ranged from $21.1 \%$ (health system, information and patient support) to $70.9 \%$ (lifestyle). No ceiling effects were present.

\section{Discussion}

This study is the first study that investigated the psychometric properties of the Dutch version of the SCNS-SF34 and newly developed SCNS-HNC among HNC patients. Psychometric properties assessed were content validity, factor structure, internal consistency, construct validity and test-retest reliability.

Content validity analyses of the SCNS-HNC showed that there were no redundant items, but that some $\mathrm{HNC}$ issues may need to be added, namely taste and olfaction, difficulty eating, eating in company and changes in appetite, coughing and breathlessness and mobility of the tongue. For some of these problems, the need for SC was already addressed indirectly, e.g. the problems on difficulty eating, eating in company and changes in appetite were addressed partly by the question on being informed about nutrition, and the problems on mobility of the tongue is addressed by the question on chewing, swallowing and speech. For the other problems/needs (taste and olfaction and coughing and breathlessness), multidisciplinary discussions are needed on the necessity to update the SCNS-HNC. In the present study, we aimed to include only those problems/needs for which SC is available. However, we realize that this aim is not consistent with the tenets of supportive care needs assessment. One of the purposes is to assist in identifying, guiding and designing the range of services that ought to be available to patients [39]. Although an item on taste and olfaction and on coughing and breathlessness may be added, the SCNS-HNC is a comprehensive PROM.

Appropriateness of the SCNS-HNC was further supported by the identified two-factor structure, namely $\mathrm{HNC}$-specific functioning, which comprises eight items on needs related to $\mathrm{HNC}$-specific functioning and problems, and a lifestyle domain, which comprises two items related to quitting smoking and drinking. Internal consistency of HNC-specific functioning was good (Cronbach's alpha $=.89$ ), while somewhat low for the lifestyle domain (Cronbach's alpha $=.60$ ), which can be explained by the fact that this domain includes only two items. We acknowledge that a domain with two items is generally recognized as less stable and thereby less reliable and less construct valid than a domain with more items [40].

Regarding the SCNS-SF34, confirmatory factor analyses showed that the five-factor structure of Boyes et al. [9] and the four-factor structure of Au et al. [16] could not be replicated in this study. Nevertheless, exploratory factor analyses showed that the four-factor structure, in which item 19 is deleted, and the domains on health systems and information and patient care and support were combined in one domain (i.e. health system, information and patient support) [16], was the best model for use in HNC patients with good internal 
Table 5 Differences in SCNS-SF34 domain scores between different patient groups

\begin{tabular}{|c|c|c|c|c|c|c|c|c|c|}
\hline \multirow[t]{3}{*}{ Characteristics } & \multirow[t]{3}{*}{ Number } & \multicolumn{8}{|l|}{ SCNS domain } \\
\hline & & \multicolumn{2}{|c|}{$\begin{array}{l}\text { Physical and daily } \\
\text { living }(n=196)\end{array}$} & \multicolumn{2}{|l|}{$\begin{array}{l}\text { Psychological } \\
(n=195)\end{array}$} & \multicolumn{2}{|l|}{$\begin{array}{l}\text { Sexuality } \\
(n=196)\end{array}$} & \multicolumn{2}{|c|}{$\begin{array}{l}\text { Health system, information and } \\
\text { patient support }(n=199)\end{array}$} \\
\hline & & Median (range) & $p$ value & Median (range) & $p$ value & Median (range) & $p$ value & Median (range) & $p$ value \\
\hline \multicolumn{10}{|l|}{ Age } \\
\hline $18-60$ years & 63 & & & $7.5(0-92.5)$ & & $0(0-75.0)$ & & $13.3(0-83.3)$ & \\
\hline$>60$ years & 138 & & & $10.0(0-85.0)$ & & $0(0-100.0)$ & & $15.0(0-91.7)$ & \\
\hline Gender & & & .11 & & .67 & & .55 & & \\
\hline Male & 134 & $10.0(0-95.0)$ & & $10.0(0-92.5)$ & & $0(0-100.0)$ & & & \\
\hline Female & 67 & $12.5(0-95.0)$ & & $10.0(0-85.0)$ & & $0(0-66.7)$ & & & \\
\hline Treatment procedure & & & .02 & & .01 & & & & .07 \\
\hline Single treatment & 92 & $5.0(0-95.0)$ & & $5.0(0-85.0)$ & & & & $11.7(0-85.0)$ & \\
\hline Multi modality treatment & 109 & $10.0(0-95.0)$ & & $15.0(0-92.5)$ & & & & $18.3(0-91.7)$ & \\
\hline Time since last treatment & & & & & & & & & .02 \\
\hline $0-1$ year & 78 & & & & & & & $19.2(0-91.7)$ & \\
\hline $1-2$ years & 60 & & & & & & & $13.3(0-81.7)$ & \\
\hline$>2$ years & 63 & & & & & & & $7.5(0-76.7)$ & \\
\hline
\end{tabular}

Significant differences are italicized

consistency (Cronbach's alpha ranged from .79 to .95). Up till now, this four-factor structure has only been proposed by $\mathrm{Au}$ et al. [16]. Other validation studies proposed the (slightly adjusted) five-factor structure of Boyes et al. [9], although these studies also acknowledged some difficulties or inconsistencies when replicating the five-factor structure [11-13, 15, 17, 18]. Okuyama et al. [18], for instance, showed that items 21 and 22 had stronger cross loadings on the health system and information domain, while originally allocated to the patient care and support domain. The same holds for Lehmann et al. [13] who found that item 30 had stronger cross loadings on the psychological domain, while originally allocated to the health care and information domain. In addition, Schofield et al. [11] reported that items 18 and 19 originally allocated to the patient care and support domain did not load (loading <.30) to one of the domains at all, and Doubova et al. [15] excluded item 31 due to high cross loadings. Finally, Brédart et al. [12] and Li et al. [17], the only two studies that performed confirmatory factor analyses, reported that residuals were correlated indicating redundancy among items. Based on these validation studies and our results, as already hypothesised by Li et al. [17], it can be assumed that one universal factor structure for the SCNS-SF34 is unlikely. The factor structure of the SCNS-SF34 may potentially differ regarding, for example, age, gender or cancer diagnosis.

To assess construct validity of both the SCNS-SF34 and the SCNS-HNC, our study defined clear a priori hypotheses regarding the (magnitude of) correlation with other PROMs and expected differences between groups of HNC patients. In our study, 96 and $89 \%$ of the hypothesised correlations were found for the SCNS-SF34 and SCNS-HNC, respectively; however, only 57 and $67 \%$ respectively, showed the hypothesised magnitude of correlation. In 11 of the 16 cases, in which the correlation as such was supported but not the magnitude of correlation, a stronger correlation was found than a priori hypothesised based on previous validation studies $[9,11-13,16,18]$ and researchers' expectations. Regarding discriminative construct validity, patients treated with multi-modality treatment in our study reported higher levels of physical and daily living and psychological needs, and patients long after treatment reported less health system, information and patient support needs. No significant differences in SC needs were found between different gender and age groups. This is in contrast to previous studies which have repeatedly shown such differences [12, 13, 16-18, 35].

A possible explanation for the stronger correlations and absence of differences in $\mathrm{SC}$ needs regarding age and gender is that all patients included in our study were at least 3 months after treatment and, in general, had low levels of SC needs, as shown by the high floor effects of 21.1-70.9\%. These high floor effects may have resulted in limited variation in outcomes and consequently in higher correlations and the absence of differences between groups. Another explanation may be that SC needs are different in $\mathrm{HNC}$ patients compared to other cancer populations (i.e. breast, prostate and mixed cancer populations) on which our hypotheses were mainly based $[9,11-13,16,18$, $34,35]$. Our results are in line with the results of Henry et al. which was published after our hypotheses formulation [23], who found relatively high correlations between total SCNS-SF34 score and HADS-D and HADS-A of $r=.44$ and .53 and no association with gender and age in $\mathrm{HNC}$ patients. 
Finally, test-retest reliability of the SCNS-SF34 and SCNS-HNC was overall shown to be good (ICC ranged from .67 to .83$)$. Only two previous validation studies $[12,15]$ also assessed test-retest reliability of the SCNS-SF34. They also showed good test-retest reliability, except for the physical and daily living domain in breast cancer patients [12].

A limitation of this study is that we included HNC patients after treatment, limiting generalizability to HNC patients undergoing treatment or other Dutch cancer populations. Therefore, we encourage the validation of the SCNS-SF34 and SCNS-HNC in patients during treatment and other Dutch cancer populations. Another limitation of this study is that although patients were asked to report any additional needs not yet included in the SCNS-HNC, patients did not participate in the developmental stage by interview or focus group. Also, critical review to assess whether all of the items were relevant for the construct being measured and cognitive interviews to determine how the items were perceived or understood by HNC patients were not performed. Main strengths of this study are the development of the SCNS-HNC, which can be used in conjunction with the SCNS-SF34, and the assessment of a wide range of psychometric characteristics including content validity, factor structure, internal consistency, construct validity and test-retest reliability.

\section{Conclusion}

In this study, a module was developed for use in conjunction with the SCNS-SF34 that measures SC needs specific for HNC patients (i.e. SCNS-HNC). The SCNS-SF34 and SCNS-HNC are valid and reliable PROMs to evaluate the need for SC among HNC patients. More research on the validation of the SCNS-SF34 and SCNS-HNC in other populations, including $\mathrm{HNC}$ patients undergoing treatment is, however, warranted.

Acknowledgments The study is funded by the Dutch Cancer Society/ Alpe d'HuZes Foundation, grant number VU 2013-5930.

\section{Compliance with ethical standards}

Conflict of interest The authors declare that they have no conflict of interest.

Open Access This article is distributed under the terms of the Creative Commons Attribution-NonCommercial 4.0 International License (http:// creativecommons.org/licenses/by-nc/4.0/), which permits any noncommercial use, distribution, and reproduction in any medium, provided you give appropriate credit to the original author(s) and the source, provide a link to the Creative Commons license, and indicate if changes were made.

\section{References}

1. Pachman DR, Barton DL, Swetz KM, Loprinzi CL (2012) Troublesome symptoms in cancer survivors: fatigue, insomnia, neuropathy, and pain. J Clin Oncol 30:3687-3696

2. Mitchell AJ, Ferguson DW, Gill J, Paul J, Symonds P (2013) Depression and anxiety in long-term cancer survivors compared with spouses and healthy controls: a systematic review and metaanalysis. Lancet Oncol 14:721-732

3. Krebber AMH, Buffart LM, Kleijn G, Riepma IC, de Bree R, Leemans CR, et al. (2014) Prevalence of depression in cancer patients: a meta-analysis of diagnostic interviews and self-report instruments. Psycho-Oncology 23:121-130

4. van der Molen L, van Rossum MA, Burkhead LM, Smeele LE, Hilgers FJM (2009) Functional outcomes and rehabilitation strategies in patients treated with chemoradiotherapy for advanced head and neck cancer: a systematic review. Eur Arch Otorhinolaryngol 266:889-900

5. Jacobi I, van der Molen L, Huiskens H, van Rossum MA, Hilgers FJM (2010) Voice and speech outcomes of chemoradiation for advanced head and neck cancer: a systematic review. Eur Arch Otorhinolaryngol 267:1495-1505

6. Langius JAE, van Dijk AM, Doornaert P, Kruizenga HM, Langendijk JA, Leemans CR, et al. (2013) More than $10 \%$ weight loss in head and neck cancer patients during radiotherapy is independently associated with deterioration in quality of life. Nutr Cancer 65:76-83

7. Mujica-Mota M, Waissbluth S, Daniel SJ (2013) Characteristics of radiation-induced sensorineural hearing loss in head and neck cancer: a systematic review. Head Neck 35:1662-1668

8. Hui D, De La Cruz M, Mori M, Parsons HA, Kwon JH, TorresVigil I, et al. (2013) Concepts and definitions for "supportive care," "best supportive care," "palliative care," and "hospice care" in the published literature, dictionaries, and textbooks. Support Care Cancer 21:659-685

9. Boyes A, Girgis A, Lecathelinais C (2009) Brief assessment of adult cancer patients' perceived needs: development and validation of the 34-item Supportive Care Needs Survey (SCNS-SF34). J Eval Clin Pract 15:602-606

10. McElduff P, Boyes A, Zucca A (2004) Girgis A. Supportive Care Needs Survey, A guide to administration, scoring and analysis

11. Schofield P, Gough K, Lotfi-Jam K, Aranda S (2012) Validation of the Supportive Care Needs Survey — short form 34 with a simplified response format in men with prostate cancer. Psycho-Oncology 21: $1107-1112$

12. Bredart A, Kop JL, Griesser AC, Zaman K, Panes-Ruedin B, Jeanneret W, et al. (2012) Validation of the 34-item Supportive Care Needs Survey and 8-item breast module French versions (SCNS-SF34-Fr and SCNS-BR8-Fr) in breast cancer patients. Eur J Cancer Care (Engl ) 21:450-459

13. Lehmann C, Koch U, Mehnert A (2012) Psychometric properties of the German version of the Short-Form Supportive Care Needs Survey Questionnaire (SCNS-SF34-G). Support Care Cancer 20: 2415-2424

14. Zeneli A, Fabbri E, Donati E, Tierney G, Pasa S, Berardi MA, et al. (2016) Translation of Supportive Care Needs Survey Short Form 34 (SCNS-SF34) into Italian and cultural validation study. Support Care Cancer 24:843-848

15. Doubova SV, Aguirre-Hernandex R, Gutiérrez-de la Barrera M, Infante-Castaneda C, Pérez-Cuevas R (2015) Suportive care needs of Mexican adult cancer patients: validation of the Mexican version of the Short-Form Supportive Care Needs Questionnaire (SCNSSFM). Support Care Cancer 23:2711-2719

16. Au A, Lam WWT, Kwong A, Suen D, Tsang J, Yeo W, et al. (2011) Validation of the Chinese version of the Short-Form Supportive 
Care Needs Survey Questionnaire (SCNS-SF34-C). Psychooncology 20:1292-1300

17. Li WWY, Lam WWT, Shun SC, Lai YH, Law WL, Poon J, et al. (2013) Psychometric assessment of the Chinese version of the Supportive Care Needs Survey Short-Form (SCNS-SF34-C) among Hong Kong and Taiwanese Chinese colorectal cancer patients. PLoS One 8:e75755

18. Okuyama T, Akechi T, Yamashita H, Toyama T, Endo C, Sagawa $R$, et al. (2009) Reliability and validity of the Japanese version of the Short-Form Supportive Care Needs Survey questionnaire (SCNS-SF34-J). Psychooncology 18:1003-1010

19. Girgis A, Boyes A, Sanson-Fisher RW, Burrows S (2000) Perceived needs of women diagnosed with breast cancer: rural versus urban location. Aust N Z J Public Health 24:166-173

20. Thewes B, Meiser B, Rickard J, Friedlander M (2003) The fertilityand meopause-related information needs of younger women with a diagnosis of breast cancer: a qualitative study. Psycho-Oncology 12:500-511

21. Bonevski B, Sanson-Fisher R, Hersey P, Paul C, Foot G (2008) Assessing the perceived needs of patients attending an outpatient melanoma clinic. J Psychosoc Oncol 17:101-118

22. Steginga SK, Occhipinti S, Dunn J, Gardiner RA, Heathcote P, Yaxley J (2001) The supportive care needs of men with prostate cancer (2000). Psychooncology 10:66-75

23. Henry M, Habib L, Morrison M, Yang JW, Li XJ, Lin S, et al. (2014) Head and neck cancer patients want us to support them psychologically in the post-treatment period: survey results. Palliat Support Care 12:481-493

24. Jansen F, Snyder CF, Leemans CR, Verdonck-de Leeuw IM (2015) Identifying cutoff scores for the EORTC QLQ-C30 and the head and neck cancer-specific module EORTC QLQ-H\&N35 representing unmet supportive care needs in patients with head and neck cancer. Head Neck. doi:10.1002/hed.24266

25. De Bree R, Verdonck-de Leeuw IM, Keizer AL, Houffelaar A, Leemans CR (2008) Touch screen computer-assisted health-related quality of life and distress data collection in head and neck cancer patients. Clin Otolaryngol 33:138-142

26. Koller M, Aaronson NK, Blazeby J, Bottomley A, Dewolf L, Fayers P, et al. (2007) Translation procedures for standardised quality of life questionnaires: the European Organisation for Research and Treatment of Cancer (EORTC) approach. Eur J Cancer 43: $1810-1820$

27. Jansen C and Lentz L. (2008) [How readable is my text?] Onze taal 1

28. Aaronson NK, Ahmedzai S, Bergman B, Bullinger M, Cull A, Duez NJ, et al. (1993) The European Organization for Research and Treatment of Cancer QLQ-C30: a quality-of-life instrument for use in international clinical trials in oncology. J Natl Cancer Inst 85:365-376

29. Bjordal K, Hammerlid E, Ahlner-Elmqvist M, de Graeff A, Boysen M, Evensen JF, et al. (1999) Quality of life in head and neck cancer patients: validation of the European Organization for Research and Treatment of Cancer Quality of Life Questionnaire-H\&N35. J Clin Oncol 17:1008-1019

30. Spinhoven P, Ormel J, Sloekers PP, Kempen GI, Speckens AE, Van Hemert AM (1997) A validation study of the Hospital Anxiety and Depression Scale (HADS) in different groups of Dutch subjects. Psychol Med 27:363-370

31. Rinkel RN, Verdonck-de Leeuw IM, van Reij EJ, Aaronson NK, Leemans CR (2008) Speech Handicap Index in patients with oral and pharyngeal cancer: better understanding of patients' complaints. Head Neck 30:868-874

32. Rinkel RN, Verdonck-de Leeuw IM, Langendijk JA, van Reij EJ, Aaronson NK, Leemans CR (2009) The psychometric and clinical validity of the SWAL-QOL questionnaire in evaluating swallowing problems experienced by patients with oral and oropharyngeal cancer. Oral Oncol 45:e67-e71

33. Terwee CB, Bot SDM, de Boer MR, van der Windt DAWM, Knol DL, Dekker J, et al. (2007) Quality criteria were proposed for measurement properties of health status questionnaires. J Clin Epidemiol 60:34-42

34. Smith DP, Supramaniam R, King MT, Ward J, Berry M, Armstrong BK (2007) Age, health, and education determine supportive care needs of men younger than 70 years with prostate cancer. J Clin Oncol 25:2560-2566

35. Boyes AW, Girgis A, D'Este C, Zucca AC (2012) Prevalence and correlates of cancer survivors' supportive care needs 6 months after diagnosis: a population-based cross-sectional study. BMC Cancer 12:150

36. Oskam IM, Verdonck-de Leeuw IM, Aaronson NK, Witte BI, de Bree R, Doornaert P, et al. (2013) Prospective evaluation of healthrelated quality of life in long-term oral and oropharyngeal cancer survivors and the perceived need for supportive care. Oral Oncol 49:443-448

37. Cohen J (1992) A power primer. Psychol Bull 112:155-159

38. Muthén, LK, Muthén, BO (2011) Mplus User's Guide. 1998-2011 Sixth ed. Los Angeles, CA

39. Fitch MI (2008) Supportive care framework. Can Oncol Nurs J 18: 6-24

40. Eisinga R, te Grotenhuis M, Pelzer B (2013) The reliability of a two-item scale: Pearson, Cronbach or Spearman-Brown? Int J Public Health 58:637-642 